\title{
Teaching through urban sensorium: urban spatiality as a smart learning environment
}

\author{
Gaana Jayagopalan ${ }^{1 *}$ and Sweta Mukherjee ${ }^{2}$
}

\author{
*Correspondence: \\ gaanaj.25@gmail.com \\ ${ }^{1}$ Department of Language \\ and Literature, Alliance \\ University, Bangalore, India \\ Full list of author information \\ is available at the end of the \\ article
}

\begin{abstract}
This paper qualitatively analyses the implication of urban sensorium as a pedagogic mode in the teaching of Urban Studies. Underpinned by the frames of smart learning environments, the paper reiterates experiencing urban ontologies as spatial learning environments. By drawing from a range of transdisciplinary and experiential modes of learning, this paper maps how an undergraduate course on Bangalore city in India served learners to critically engage with and experience spatial urban ontologies both digitally, and in real-world experiences of learning, furthering learner autonomy and reflection. The methodological prisms of this paper are autoethnography and critical reflection. It is organised around enabling learners recognize the experiential, embodied urban spaces through the urban sensorium via real-life engagements with urban spaces, and creation of digital portfolios that map this learning. Findings from the learners' knowledge of sensory learning, the city's intersectional aspects, and the student's embodied and emplaced self in built environments and digital spaces are analysed via cognitive and affective-reflection levels; the course instructor's reflection is analysed via a process-reflection level. These reflections hold implications for the pedagogy of urban studies in undergraduate classrooms by foregrounding spatiality and urban sensorium as significant critical and affective pedagogic tools. The paper has also accommodated critical engagement with an external faculty member as a co-author, in order to manage any bias or researcher subjectivity in the design.
\end{abstract}

Keywords: Urban sensorium, Smart learning, Reflective research, Emotional intelligence development, Student self-oriented learning model, Reflective pedagogy

\section{Introduction}

Classrooms have always been characterised by a dynamic spatiality that encourages focused interactions and learner involvement. However, classroom teaching continues to be limited, in its understanding of space, to the traditional notions of classrooms. Increasingly, literature points to a significant development in research on pedagogy that learning is a cognitive as well as emotional experience (Hascher, 2010; Tyng et al., 2017). Higher Education spaces, however, have mainly viewed learning as a purely cognitive experience (Mortiboys, 2005). A shift to higher education is not merely an academic shift but also includes readjusting roles, reduced parental monitoring, need to possess an increased sense of responsibility-sometimes coupled with geographical adjustments with shifts to different cities (Stallman, 2010). Therefore, there is an increased need to

(c) The Author(s) 2022. Open Access This article is licensed under a Creative Commons Attribution 4.0 International License, which permits use, sharing, adaptation, distribution and reproduction in any medium or format, as long as you give appropriate credit to the original author(s) and the source, provide a link to the Creative Commons licence, and indicate if changes were made. The images or other third party material in this article are included in the article's Creative Commons licence, unless indicated otherwise in a credit line to the material. If material is not included in the article's Creative Commons licence and your intended use is not permitted by statutory regulation or exceeds the permitted use, you will need to obtain permission directly from the copyright holder. To view a copy of this licence, visit http:// creativecommons.org/licenses/by/4.0/. 
evaluate learner-learning experiences in higher education spaces. In this context, redefining learning spaces and re-designing pedagogy to empower cognitively as well as emotionally competent learners and enable them to make their own learning choices is a step towards learner autonomy. Learning is an amalgamation of cognitive and emotional processes; a learning process where students learn through engagement with the process and reflection of the process is essential to creating a holistic learning environment (Fomichov \& Fomichova, 2017).

The present work is an attempt in this direction. It reflectively analyses the pedagogic administration and facilitation of a beginner-level undergraduate course on understanding the cityscapes of Bangalore, India, through a reading of the city as an urban sensorium. While several works have established the significance of working through urban sensoria, the strength of this paper lies in engaging with doing urban social ontology via urban sensorium as a pedagogic mode (Zhuang et al., 2017). We draw from a range of transdisciplinary and experiential modes of learning to highlight the real-time and digital learning environments both inside classrooms as well as outside of it. How does the pedagogy of urban studies contribute towards experiential and reflective learning of urban spaces? How can this pedagogy be extended to enable a conceptualisation of urban spaces as smart learning environments? How does this further propel the pedagogy of spatiality as an enabler of kinaesthetic and embodied learning that can inform the learner's use of digital medium for their learning? These are some questions that have guided this research explication.

The paper is organised around instantiations of classroom experiences, on-field experiences, and critical reflection of the digital assessments, all of which were continuously evaluated for their strength as different learning environments. The paper posits urban sensorium pedagogy as a smart learning environment, coupled with digital assessments (Hwang, 2014), as smart learning towards Urban Studies. The assessment culminated in a digital impression of the experience, accompanied by a reflection essay, to enable learners recognise their mapping of the urban sensorium. Here, we import Jon Dron's use of a functional characterization of smart learning environments that "actively nurture learning, however that may be achieved" (Dron, 2018, p. 1). Dron expands the otherwise limited sense of digitality-blended learning that determines the 'smartness' in learning environments. For him, the purview of 'smart' learning environments is

the configuration of its parts - humans and others - and their interactions ... to consider smartness as an emergent consequence of dynamic interactions between the environment's constituent parts, including those of its human inhabitants and the artefacts and structures they wittingly or unwittingly create. In such an environment ... smartness emerges as a result of structure and interaction, whether or not either aspect is mediated or enacted through digital technologies. (Dron, 2018, pp. $2-3)$.

Drawing from this, it was observed that students were able to locate their individual learning alongside skills accrued in the process of this urban experiential learning mode. This also foregrounds an embodied learning through a material and digital engagement with space and its social construction. The sensorium as a concept emerges in the twentieth century writings of European cultural theorists like Walter Benjamin. Benjamin's 
reading of the twentieth century was that the human condition is increasingly being characterised by perceiving the world driven by technical splendour, primarily visual in nature, as neurological shocks (Buck-Morss, 1992). Benjamin critique a disembodied experience of the gifts of technology-film, photography, music-all rendered technically in a disembodied space and time where a user can move to another time and space without really being in that time and space. By foregrounding the urban sensorium as a significant critical, affective pedagogic tool, we generate reflections about learners' knowledge of the sensory learning, the city's intersectional aspects, and more significantly, the student's embodied and emplaced self in the built-environment.

The methodology of this article is provided by autoethnography (Hughes et al., 2012) and reflective research. It is triangulated by a reflection of the pedagogy through a combination of in-class student-teacher reflections, on-field experience of urban sensorium via student participation, and reflection of learning through the exercise of mapping a spatial contour in the city via sensory experience in digital learning spaces. The paper has also involved the engagement of an external faculty member as a co-author, in order to manage any bias or researcher subjectivity that may have arisen in the design. We draw directly from course materials as well as student work to support the reflections on the course. The following sections also highlight how the learners were able to actively experiment with digital modes to render their work. It explicates how learners concretise their experience of being in the city and kinesthetically learn from it, how their reflective observational strategies enabled their mapping skills, and how they were able to conceptualise the abstract sensorium experience in creative ways.

The paper has implications for teachers and for other stakeholders. The urban space here becomes the medium and as well as the content of the teaching/learning process. This opens up the notion of spaces in pedagogy as 'one that is occupied for teaching' to spaces themselves becoming pedagogic. Understanding alternative spaces and their relationship with learning will enable educators, students, curriculum designers, and administrators to incorporate this notion into pedagogic policy and practice.

\section{Overview of pedagogy and spatiality}

One of the major inspirations that backed the design and the facilitation of the course was a need to explore alternate pedagogical spaces. Classrooms have always been dynamic spaces encouraging interactions and learner involvement. However, 'classroom' limits the understanding of space vis-a-vis traditional notions of classrooms. The focus of any educational process is the development of a learner's critical analysis competencies where "these capacities are often hindered to be nurtured in a packed small pot" (Park \& Choi, 2014 p. 751). In higher education, teaching-learning processes need to be directed toward the development of higher order thinking skills. Thus, a course that studies the impact of a pedagogy centred on understanding the urban sensorium as a space of and as a space for learning, can lead to significant perspectives in higher education.

The course "Reading Cityscapes: Bangalore Histories" on which this paper is based also brings forth another significant component: experiential learning. Learners and their experiences become vital to the understanding of the city and, by extension, of spaces. By making learners proactive participants in their own learning process using 
"inductive reasoning" as a pedagogical process, experiential learning "creates opportunities" for "data learning" as opposed to "assumption learning" (Hawtrey, 2007). This, in turn, furthers the vision with which this course was designed. Learners often retain only parts of what they hear whereas they retain majorly when they actually do (Senge, 1990). The most significant aspect of this learning is learners' personal involvement with the process of learning and then basing their knowledge on their experiences.

\section{Development}

\section{The research context}

The study concerns "Reading Cityscapes: Bangalore Histories", a 3-credit course with 3 contact hours a week offered to first-year undergraduate students at a university in Bangalore. 81 students enrolled into the course. One of the objectives of this research thrust area includes introduction of courses about the city of Bangalore.

Urban Studies has established itself as significant field of enquiry today. Urban dwellers are on the increase across the globe. The urban is the driving impulse of our contemporary economic and cultural change (Amin, 2007). Bangalore occupies an important locus in this urban paradigm. As knowledge-builders vested heavily in working towards developing more important trajectories of cultural studies in the Indian context (Sawhney, 2019), the need to specifically develop knowledge around the city of one's academic labor-Bangalore-is imperative.

The course was guided by the belief that the urban sensorium as a pedagogy will aid in creating an understanding of Bangalore as a more corporeally-perceived, and socially sensed space. In turn, urban spatiality comes to be established as a smart learning environment. Engaging with Bangalore has also seen some significant research. Research in the area of urbanity of Bangalore has primarily focussed on economic and IT-enabled structure (Stallmeyer, 2010), water histories and sustainability studies, and urban loving and sustainability (Revi et al., 2014). However, there is limited research to understand the pedagogic import of Bangalore as urban spatiality. The present paper discusses the course in this light. As a part of the course, students were exposed to documentaries and curated material on Bangalore which would help them map their sensory perceptions of the city. Through reflections and discussion, students then were encouraged to visit these sites and connect their classroom learning to their actual perceptions of the city spaces.

The course design is drawn from sensory ethnography. Students were encouraged to probe important questions about the city throughout the course. These included questions such as: How does one locate the sensoriality of experiencing urban spaces? What would some of the experiences of mobility in the city mean to its dwellers? How does immobility and the city come to be examined? What newness does a sensory reading of urban spaces bring to one's engagement with the space?

\section{Course content}

The course 'Reading Cityscapes: Bangalore Histories' is an elective offered to students of the first-year undergraduate program at the University. The course is initiated as an attempt to generate new knowledge about the urban nature of Bangalore, both pedagogically as well as experientially. With a constitution of student population that is a 
mix of native as and non-native learners, the course also aims to understand the diverse engagements that learners bring to their experience of the city.

Typically, the class includes students from various disciplines including Business, Humanities and Social Sciences. The course enables students to think of the concept of 'the city' as a dynamic entity and analyse how our interaction with, the city produces knowledge about urban spatialities. The central focus of the course is to help students develop a sensory approach to understanding the city.

Reading Cityscapes is built with the following outcomes:

- Illustrate a comprehensive knowledge of an informed sense of 'city' through critical enquiry;

- Generate critical readings and writings about various aspects of Bangalore spatially;

- Examine and revise various concerns that the discipline engages through academic presentations and research;

- Develop a critically sharp outlook towards reading and understanding of narrations of Bangalore, and

- Generate readings about the city through sensory perceptions as analytical frameworks.

Through the course, the course instructor wished to take students through an experiential, informed ontological reading and engaging with built environments.

\section{Course design}

The entire course was envisioned around engaging with the city through the urban sensorium, in-class readings, lectures and discussions involving several literary, political and cultural discourses around the city. These were meant to primarily help students develop a nuanced sense of experiencing the urban. Readings included those that mapped the historical and cultural development of Bangalore, the role of public activism in developing a certain cultural currency of Bangalore; contestations over public spaces, among others. These readings were contextualised to be read alongside the emerging contemporary debates in and around the city. ${ }^{1}$ Students were also introduced to thinking about spatiality differently. They were encouraged to move away from the most dominant mode of engaging with the city - the visual medium-and attempt to work through other sensory perceptions.

At the outset, students were instructed to tour the campus and make notes about the sensory perceptions of what they observed on campus. These observations enabled them to think about spaces differently. For instance, students noted that the campus cafeteria is noisier during the breaks, obviously due to more student footfall, than during class hours when it was largely unoccupied. Here, they noted the intersection of the visual with auditory sense: a visually empty cafeteria, for instance, also meant nearly no noise. This led them to understand that one kind of sensory perception also works alongside other sensory perceptions to generate meanings. This was one of the ways to enable

\footnotetext{
${ }^{1}$ For instance, Bangalore's Town Hall, an important historical architectural space was fairly unknown until the protests over the Citizenship Amendment Act became a robust activist and student-led protest at Town Hall. Town Hall's presence in the public imagination drastically changed, an evident idea that emerged in many of the classroom discussions.
} 
students to recognise the embodied sense of spatialities generated through a reading of sensory grammar.

Following their interaction with the cafeteria space and their subsequent reflections on it, students were required to discuss the readings in class. They were also provided feedback on their mapping of the sensory experiences. Students' field experiences, their reflections of the same, collation and critical analysis of the notes were the central components of the pedagogy here. The outcome of the assessment was going to be evaluated based on the digital curation done by the student. They were given the freedom to choose a platform for the same. Instagram was one platform extensively used by students. Here, many students were able to clearly elucidate how the visual and aural were also guided by taste, tactile, auditory, olfactory sensory perceptions. Some others also developed websites and blogs to host their content. ${ }^{2}$ This digital production of knowledge for assessment was also an important dimension of the assessment design.

\section{Methodology and design}

We work with two theoretical frameworks to argue for the urban social ontology via urban sensorium as a critical and affective pedagogic tool: one emanates from within Urban Studies while another from studies in pedagogy and assessment. Borrowing from these two frames, we explicate how the mode adopted in the course increased student learning both at the level of domain-based comprehension of studying urban spatialities, as well as enabling their general skill sets including written skills, speaking skills, critical and analytical skills, and communication skills. The levels include the cognitive reflection-level; the affective-reflection level, and the process-reflection levels. The need to recognise both the human sensorium and its embodied presence, and its resulting urban sensorium paradigm as a pedagogic mode in the mapping of the city's built-environments is central to the paper here.

Guided by autoethnography (Hughes et al., 2012) and teacher reflection as methodological pegs (Jakeman et al., 2017), this paper explores the following questions:

1. What pedagogical implications does the urban sensorium approach hold out for the integration of a kinaesthetic, affective learning mode in the facilitation of introductory urban studies courses?

2. Can these pedagogical implications also be valid to explore alternative spaces (spaces apart from the classrooms) as pedagogical spaces, especially in the digital context?

3. Can the urban space here become the content and the medium to understand spatiality within the pedagogical context?

These questions function as interpretive frames to critically reflect on the course, and for this, Jan Fook's (2011) critical reflection as research is used as the interpretive prism. Fook locates critical reflection as a research method for practitioners of various professions to reorient, organise and reconfigure their own learning experience as a way of adding value to their professional practice. He says, "participants begin by presenting

\footnotetext{
${ }^{2}$ The digital portfolio also served as a mode of curating some interesting work on other platforms like Google Sites, 'Wixsite' and other blogging platforms.
} 
a story of their experience which they believe is crucial to their learning about their professional practice" (Fook, 2011, p. 56). Fook also delineates two important stages in this reflective learning. Stage 1 is when the participant traces certain fundamental assumptions of their practice, often to do with power and social context. The second stage is characterised by an awareness of these assumptions that may be reorganised and reworked leading to new approaches in one's practice. In a similar vein, this line of inquiry is adopted here to orient the course development as the first stage where the assumptions are drawn together to create a course design, and Stage 2 is the reflective exercise that helps place many of these assumptions within a larger personal as well as a social context of critical and affective pedagogy. Further, this paper is also informed by research that argues for a development of reflection in the research environment from which they operate (Attia \& Edge, 2017; Higgs et al., 2011).

To provide a conceptual understanding of the sensorium, we borrow from BuckMorss' reading of the 'corporeal sensorium' in Walter Benjamin's work on Paris. BuckMorss argues that the sensorium can be understood as a "form of cognition, achieved through taste, touch, hearing, seeing, smell-the whole corporeal sensorium" (BuckMorss, 1992, p. 6). The idea of the urban sensorium, therefore, is fairly straightforward and is drawn from an understanding of developing a sense of the city through the five senses: sight, sound, smell, taste and touch (Krieger \& Holman, 2007). Here, we restrict ourselves to an understanding of primarily the corporeality of the sensorium as a pedagogic mode rather than the more often associated category of the aesthetic. For this, we use excerpts from student works as representative impressions of their learnings from the course ${ }^{3}$ alongside their reflective essays that mapped their learning. These function as illustrations of engaging with the urban sensorium of Bangalore as a pedagogic mode. Their works serve to illustrate the critical, pedagogic, affective potential of enabling urban sensorium readings as an engaging way to make sense of the social ontology of urban spaces.

\section{Assessment}

The assessment was incremental across four levels of formative assessment submissions, culminating in a summative assessment of a reflective essay. Each student was directed to make a comparative analysis of two sites in the city of Bangalore through a sensory reading of the sites as a way of urban meaning-making. Each student was to regularly visit both sites and maintain a journal of their observations to marks any similarities, differences and significant sensory perceptions that stand out due to its context. The learner was also directed to propose two sites clearly demarcating the rationale for the choice of the two. These had to be justified for the choice of comparison either by its similarities, or stark differences, or their location, or history. Following instructorfeedback, they had to develop their content. The final submission was to culminate in a digital portfolio of the entire work and a reflective essay clearly outlining the learning acquired in the process of the work. The digital portfolio was chosen as the assessment

\footnotetext{
3 The learners' illustrative writing used here has been retained as is, without making improvements to the style or grammar. This is deliberately done because style of writing was not one of the central aspects of the course's administration. Additionally, and more significantly, the work is rendered verbatim in order to retain their voice and their account's authenticity.
} 
platform as this enables a multi-modal audio-visual curation of learner experience. The essay had to include the following:

1) Mapping the two sites and identifying the learning through sensory exploration of the two spaces

2) Learnings from the on-field activities with a list of 5 skills that were honed during this exercise.

3) Learnings from organising information, observation and materials gathered to put the portfolio together

4) Elaborating the sources of learning

5) Visual creative map of the comparative spatial analysis

6) Mastering Knowledge and Skills accrued in the semester through journaling, observation, critical thinking and analysis

7) Presentation: Completeness and quality of the work documented and presented

At the end of these assessments that progressively built one from another, it was believed the student will be able to:

a) Identify areas of enquiry with regard to culture and the city;

b) Describe the discursive construction and sensory mapping of the identified domains in the city;

c) Evaluate, compare and contrast various modes of knowledge used to represent work;

d) Articulate clearly and critically aspects of reading sensory perceptions of the city;

e) Write clearly and articulate one's critical analysis in the sensory reading of city spaces;

f) Reflect in thought, writing, and other creative outputs the importance of recognising various learnings;

g) Create work that maps the readings of sensory perceptions of the city sites chosen, and

h) Collate, organise and assimilate various observational knowledge and transform them into critical and analytical points about the city and the self.

\section{Results and discussion}

Locating the course in a reflective environment of learning was central for the course. The digital submission assignment was to be developed across the semester, drawing from class discussions and instructor-feedback. Therefore, the course content was developed keeping this crucial reflective element as central to its administration. Attia and Edge (2017) trace the development of 'becoming a researcher', in their work on reflection as a research methodology. It is useful to reproduce their idea here to help contextualise our curricular aims and outcomes better:

Embedded in and emerging from their contexts, therefore, reflexive researchers open themselves up as one element of the phenomena that are to be investigated. Moreover, in such investigation, while prescribed and learned methodological procedures may well be useful, a developmental approach to research methodology (and 


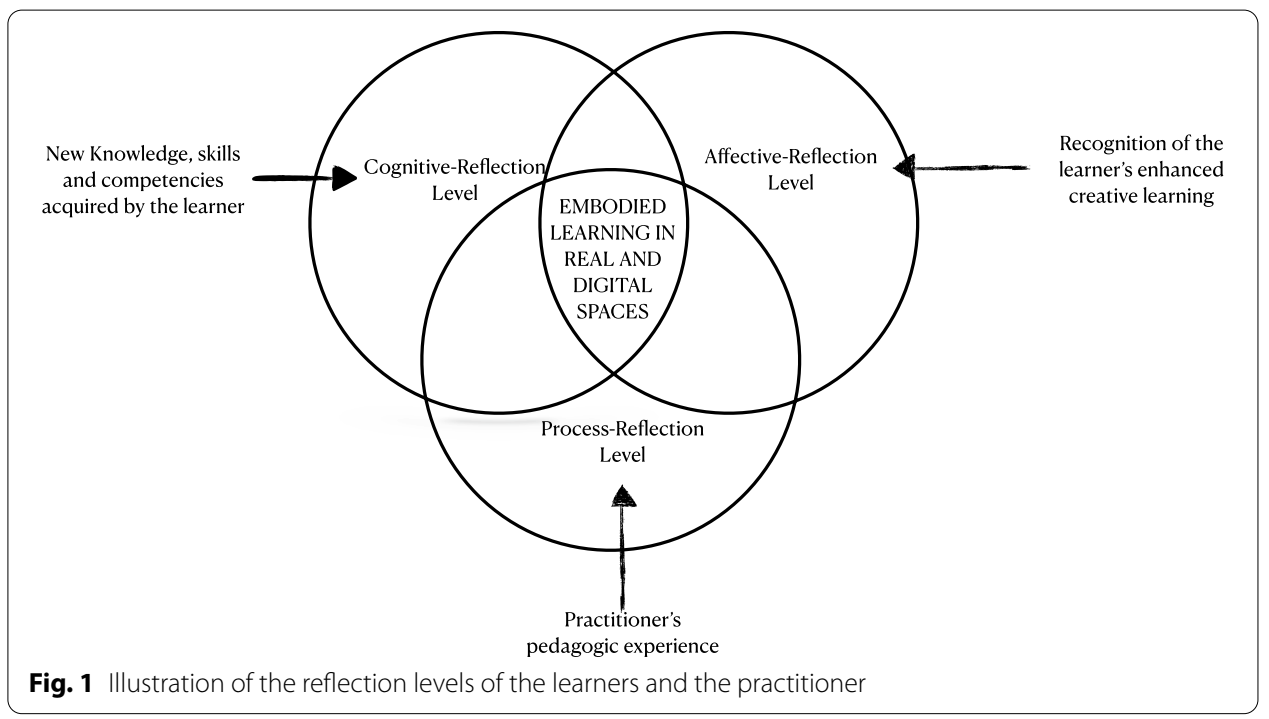

a becoming approach to being a researcher) will be equally open to the possibility of shifting insights, emergent goals, and evolving methods in the pursuit of findings more significant than those that initial research questions might have foreseen. The role of reflexivity ... involves raising awareness of its processes with the dual aim first of enriching one's lived experience, and then articulating this awareness as a contribution to the deepening of understanding of the field. (Attia \& Edge, 2017, p. 36)

Thus, reflection seeks to establish an embodied learning experience. Fomichov and Fomichova (2017) elucidate the development of the Student Self-Oriented Learning Model (SSOL-model) to map the benefits of acquired knowledge coupled with life experience as beneficial for self-cognition and self-construction. Drawing on this, we advance the learner-recognition as acutely being informed by spatiality of learning, both real and virtual. Figure 1 is an illustrative representation of this intersectional matrix that generates an embodied learning in real and virtual spaces. Guided by reflection as a research method, the discussion here is oriented along three major levels of reflection: the cognitive-reflection level that delineates and critiques the new knowledge acquired and new skills learnt in the course by the learner. Affective-reflection level draws from student responses that point towards enhanced creative learning, recognition of the embodied learner, and informed decision-making. Process-Reflection level ties both the cognitive and affective reflection ideas drawn from student work to locate the course's administration within the pedagogic experience for the practitioner working out of specific institutional structures.

\section{Cognitive-reflection and affective-reflection levels}

This section examines the different responses given by students that allude to their new learnings and skills (cognitive reflection) and a consciousness of their embodied selves in the process of this experiential learning (affective reflection).

From student work emerged a sense of perceiving the city through an informed lens, aided by the sensorium. Thus, with the course, the attempt was also to move towards an ecology of urban sensorium informed by the presence of the learner in the space and 
time and record the observations to develop a social-ontological sense of the urban space being investigated. With students at work, it was clear that the affective and kinaesthetic learning played a significant role in their cognitive reflections. Role of affective learning in pedagogy has been increasing, especially with a need to locate advancing cognitive levels through a well-informed affective mode that draws from learners' interests, emotions, attitudes and motivations. Such pedagogic styles sure do assist students in decision-making, creativity and rational behaviour, thus maximising learning outcomes (Bamidis, 2017).

Students pursued several spaces, and it was fascinating to observe how in many instances, the spaces were visualised entirely differently. In a work mapping Cubbon Park, an important public space in Bangalore's cultural imaginary, the student notes "Places like Cubbon Park can be used as political platform. For instance, on 13/01/2020, the CAA protests at the park has shown a musical twist. Here a bunch of 30 professional musicians decided to protest ... their front in the form of a rap." (Bhatnagar, 2020). Similarly, another student exploring the city on a bus ride claims: "In the evening, smell perceived is a billion times different ... Sweaty armpits, soiled shoes, smoke and pollution ... give an idea of how exhausting it is for everyone living in this city." (Periwal, 2020).

An important implication of the sensorium as pedagogic mode was to enable an embodied learning experience of the self in the built environment. This embodied emplacement of the learner is further facilitated by their attention to sensory perceptions informed by a kinaesthetic and affective learning. In reflecting on these affectations, a criticality was also noticed, especially in students' recognition of the intersections of class, labour, politics, and gender-related questions. Consider the two following responses from the reflective essays of two learners, presented here in some detail as they appear in their final submission:

\section{Reflection Excerpt 1}

During my research on the Cubbon Park, I had conducted an in-detail comparative analysis of the landmark on weekends, when compared to weekdays. I chose this particular location because I believe it can be deemed as the "pride of Bangalore" and I like to call it "The Crown Of The Garden city". If a tourist asks a Bengalurean about places they should visit during their time in the city, they will definitely have Cubbon Park in the top-five of their list. I was also keen on comparing this location to "itself", by that I mean on weekends and weekdays. This is because, I observed a wide difference in terms of sensory perceptions when I had visited the landmark on a Tuesday, compared to when I went on a Sunday.

While paying attention to sight I observed that there were a lot more people on weekends compared to weekdays at the various spots within Cubbon Park. I figured that this might be because people are not tied down by the daily routines on weekends, when compared to weekdays. Hence, they come to Cubbon Park to "take a break". In terms of smell I observed that on weekdays there was a very distinct smell of nature like the smell of trees, wet mud and flowers. This is probably because on weekdays there are hardly any people, food vendors, dogs etc. However, on weekends I observed that the place was brimming with life. Hence, I could sense a series of mixed smells ranging from the smell of the snacks from the street stalls, dogs pranc- 
ing around and just a subtle smell of the trees and blossoming flowers.

When it comes to sound I noticed that on weekdays the main sound I could hear was of the birds chirping, wind gushing and the subtle sound from the movement of trees. There was hardly any sound made by people. On weekends however, I could hear a lot of chitter-chatter of people, sound of cars honking, dogs barking, street vendors calling out for customers and of course wonderful music from the performers performing on the "bandstand".

When it comes to touch, I recall the touch of the grass, barks of the trees and soft fur of the dogs. I also recall the vibrations I felt when from the ground when there were performances on the bandstand on weekends.

When it comes to taste I remember the taste of the yummy street food sold by the street vendors on weekends. However, I observed that there was lesser snacks to taste when I went on weekdays. I figure this is because of the street vendors have noticed that a lot lesser people come to the park on weekdays. Hence, they can get better business elsewhere. During my time there, I couldn't help but wonder how this "space" could have just been some barren land used to construct skyscrapers. However, due to the beautiful spread of green foliage of trees, flowers and small ponds. The space has become a famous garden that is like the "lungs of Bangalore". Cubbon Park is indeed a wonderful pace to understand the various dynamics of sensory perceptions. This landmark will not only heighten these perceptions but will also get you in touch with wonders of nature.

\section{Reflection Excerpt 2:}

Communication skills played a major role in my assignment. It includes interpersonal interactions, verbal and non-verbal communications and written communication. Being a business student, communication is an essential part of my career and also in my personal life to develop and maintain relationships. I got an opportunity to speak to a lot of people and one of them was the Director of Horticulture in Lalbagh which improved my interpersonal interaction. Speaking to multiple people revealed their interpretations of the place which increased my understanding and opened the doors to things which were unknown to me.

Non-verbal communication in the form of the facial expression of the people who were present in those places had to be observed to understand how their behaviour is affected by the space like in High Court people were often tensed and anxious whereas in Lalbagh people had a relaxed expression. These were the communication skills developed on-field. In off-field work, writing skills were the main form of communication. Analysing and interpreting all the observations, developing connections and giving a structure to the entire assessment was possible only through the writing. This enhanced my vocabulary, sentence formation and in all my writing skills which is very important in the academic world.

Both these excerpts, although only representative, capture the larger affective, kinaesthetic and embodied mode of doing city studies informed as an urban sensorium. Memories invoked by smell, the city's intersection with social questions of class, as well as these informing the student's own learning is to be noted here. 
Process-reflection level: locating practitioner and institutional critiques, and pedagogical recommendations

In this reflection level, the course instructor reflects through the facilitation of the course on the very practice of the pedagogy. One of the important reflections that emerges from a critical look at the course facilitation is the manner in which increasingly curriculum needs to bridge the gap between theory and praxis. Here were a set of students from diverse disciplinary backgrounds in their first year of instruction. They were not equipped to fully comprehend the philosophical and theoretical underpinnings of the 'social and ontological dimensions of studying the urban'. It was imperative that this gap needed to be bridged. The best way to enable this was to encourage students to be able to establish the links between the theoretical modes of analysing the city, to actually going about doing it. ${ }^{4}$

However, much was also learnt as a way of retrospective reflection for the instructor. An important measure was the nature of the digital work presented by the students. While many students learnt from their own practice of using digital media, the actual use of the digital platforms to host their work itself was not actively considered as a part of the pedagogic practice. This was assumed to be covered through feedback sessions. However, in hindsight, an inclusion of sessions on developing digital tools will make learners far more curious and creative, thus equipping them with another set of skills not envisioned earlier in the course becomes a necessity. This reflection has been further enabled primarily through the current situation of the pandemic, that has urged us practitioners to reconsider our pedagogic modes. Ever since the move to work with technology in higher education has been necessitated with the pandemic, in hindsight, the primary course instructor realised that they could have used several important tools to enable learning, writing, collaborative knowledge development and sharing as active parts of the pedagogy. As an instructor, the primary author failed to equip with the necessary digital tools to be able to render the digital portfolio through modes other than the most popular ones chosen by the students. Students could have been introduced to audio recording apps to help them work with sound bites of the city in a more informed manner. The institutional LMS could have been built into the course in a far stronger way that would have worked well to curate content about the city and generate institutional digital knowledge.

An important challenge faced by the course instructor was the class number. A course that offers exciting opportunities to learn is likely to attract students, but in some cases, students also had to choose the course because of non-availability of other courses. Therefore, their investment in the course was far lesser than those who had chosen the course out of their own volition. This was also reflected in some of their reflective essays.

An area of serious concern is also the possibility of the course being offered by another instructor, due to various administrative reasons, who has little or no experience in carrying this sort of a pedagogy. In such a case, a digital tool-kit to help the instructor work with the course and achieve the outcomes outlined will be far more successful.

\footnotetext{
${ }^{4}$ Michel de Certeau's 'Walking in the City' served as an interesting point to begin with, especially with the opening visual image of New York vis-à-vis its alleyways. This provided a good visual and cognitive analogy for students to begin thinking about Bangalore, too.
} 


\title{
Conclusion
}

This paper has reflected on pedagogical implications for the integration of a kinaesthetic, affective learning mode in the facilitation of introductory urban studies courses. Foregrounding the urban sensorium as a smart learning environment, an important implication of this reflective research has been in recognizing the success of the pedagogic mode of the urban sensorium. Considering this, an action-research with the course can be initiated to understand its long-term effect both for students in the long-run and the sustainability of the projects worked on by students. Since the sustenance of continuing many of the digital platforms is not worked within the course, a student may not necessarily continue to contribute towards building their digital repository. This can be worked within the pedagogic mode and envisioned in terms of a longer research plan to see its overall effectiveness. It has been illuminating to note that this research also opens up experiential pedagogy via spatialities, an idea that can be highly useful in other pedagogic contexts, too. This sort of a research plan can culminate in an action-research design that will work towards a more focused digital capstone-assignment for students that will also enrich the pedagogy of urban studies, as well as create new knowledge about cities made available digitally.

\section{Abbreviations}

ICT: Information and Communications Technology; LMS: Learning Management System; CAA: Citizenship Amendment Act, 2020.

\begin{abstract}
Acknowledgements
We would like to thank the students enrolled in this course for their engaged learning and reflections.

Corresponding Author: Gaana Jayagopalan is Associate Professor with the Department of Language and Literature at Alliance University, Bangalore. She teaches courses in literary studies. Her areas of interest include colonial discourses; Indian English Fiction; postcolonial literatures, Blue Humanities, and Higher Education in India, among others.

Second Author: Sweta Mukherjee is an Assistant Professor with the Department of English and Cultural Studies at Christ University. She has also been working with the Teaching Learning Enhancement Cell at the University since 2015 and has worked extensively on the teaching, learning, and assessment practices across the University.
\end{abstract}

\section{Authors' contributions}

GJ administered the course and assessments, and developed the research outline and findings. SM contributed to the development of literature and provided a dyad review to manage any research bias that emerged in the design. All authors read and approved the final manuscript.

\section{Funding}

This research has not been funded.

\section{Availability of data}

Data Sharing is not applicable to this article as no datasets were generated or analysed during the current study.

\section{Code availability}

NA.

\section{Declarations}

Competing interests

The authors declare that they have no competing financial and non-financial interests.

Research Involving Human participants/Animals

NA

Ethics Approval

NA

Informed consent

NA

Author details

${ }^{1}$ Department of Language and Literature, Alliance University, Bangalore, India. ${ }^{2}$ Department of English and Cultural Studies, Christ University, Bangalore Central Campus, Bangalore, India. 
Received: 14 September 2021 Accepted: 3 January 2022

Published online: 11 January 2022

\section{References}

Amin, A. (2007). Re-thinking the urban social. City: Analysis of urban trends, culture, theory, policy, action, 11(1), 100-114. https://doi.org/10.1080/13604810701200961

Attia, M., \& Edge, J. (2017). Be(com)ing a reflexive researcher: A developmental approach to research methodology. Open Review of Educational Research, 4(1), 33-45. https://doi.org/10.1080/23265507.2017.1300068

Bamidis, P. D. (2017). Affective learning: Principles, technologies, practice. In C. Frasson \& G. Kostopoulos (Eds.), Brain function assessment in learning (pp. 1-13). Springer International Publishing.

Bhatnagar, G. (2020). Crown of the garden city. https://thecubbonpark.blogspot.com

Buck-Morss, S. (1992). Aesthetics and anaesthetics: Walter Benjamin's artwork essay reconsidered. October, 62, 3-41

Dron, J. (2018). Smart learning environments, and not so smart learning environments: A systems view. Smart Learning Environments, 5(1), 25. https://doi.org/10.1186/s40561-018-0075-9

Fomichov, V. A., \& Fomichova, O. S. (2017). The student-self oriented learning model as a paradigm for supporting and developing emotional intelligence and creativity. In Informacijska Druzba-IS 2017. Proceedings of the 20th international multiconference-IS, 11-16.

Fook, J. (2011). Developing critical reflection as a research method. In J. Higgs, A. Titchen, D. Horsfall, \& D. Bridges (Eds.), Creative spaces for qualitative researching: Living research (pp. 55-64). SensePublishers. https://doi.org/10.1007/ 978-94-6091-761-5_6

Hascher, T. (2010). Learning and emotion: Perspectives for theory and research. European Educational Research Journal, $9(1), 13-28$

Hawtrey, K. (2007). Using experiential learning techniques. The Journal of Economic Education, 38(2), 143-152. https://doi. org/10.3200/JECE.38.2.143-152

Higgs, J., Titchen, A., Horsfall, D., \& Bridges, D. (2011). Creative spaces for qualitative researching: Living research. In Practice, education, work and society Volume 5. Sense Publishers.

Hughes, S., Pennington, J. L., \& Makris, S. (2012). Translating autoethnography across the AERA standards: Toward understanding autoethnographic scholarship as empirical research. Educational Researcher, 41(6), 209-219. https://doi. org/10.3102/0013189X12442983

Hwang, G.J. (2014). Definition, framework and research issues of smart learning environments-A context-aware ubiquitous learning perspective. Smart Learning Environments, 1(1), 4. https://doi.org/10.1186/s40561-014-0004-5

Jakeman, R. C., Henderson, M. M., \& Howard, L. C. (2017). Reflective pedagogy: The integration of methodology and subject-matter content in a graduate-level course. Teaching in Higher Education, 22(2), 207-221. https://doi.org/10. 1080/13562517.2016.1237494

Krieger, M. H., \& Holman, T. (2007). A Dozen, “Tamales!": Documenting the aural urban sensorium. Journal of Planning Education and Research, 27(2), 228-230. https://doi.org/10.1177/0739456X07308575

Mortiboys, A. (2005). Teaching with Emotional Intelligence: A Step by Step Guide for Higher and Further Education Professionals. London: Routledge.

Park, E. L., \& Choi, B. K. (2014). Transformation of classroom spaces: Traditional versus active learning classroom in colleges Higher Education, 68(5), 749-771. https://doi.org/10.1007/s10734-014-9742-0

Periwal, A. (2020). Bus Blogs. https://sites.google.com/view/busblogs/exploring-our-senses/perception-of-sound

Revi, A., Jain, G., \& Sami, N. (2014). Sustainable cities initiative city report (Issue January). https://doi.org/10.24943/scicr. bangalore.2014

Sawhney, R. (2019). Decolonising cultural studies. Artha - Journal of Social Sciences, 18(3), 25-42. https://doi.org/10.12724/ ajss. 50.2

Senge, P. M. (1990). The fifth discipline: The art and practice of the learning organisation. Doubleday/Currency.

Stallman, H.M. (2010). Psychological distress in university students: A comparison with general population data. Australian Psychologist. 45

Stallmeyer, J. C. (2010). Building bangalore: Architecture and urban transformation in India's Silicon Valley. Taylor \& Francis.

Tyng, C. M., Amin, H. U., Saad, M. N. M., \& Malik, A. S. (2017). The influences of emotion on learning and memory. Frontiers in Psychology, 8, 1454. https://doi.org/10.3389/fpsyg.2017.01454

Zhuang, R., Fang, H., Zhang, Y., Lu, A., \& Huang, R. (2017). Smart learning environments for a smart city: From the perspective of lifelong and lifewide learning. Smart Learning Environments, 4(1), 6. https://doi.org/10.1186/ s40561-017-0044-8

\section{Publisher's Note}

Springer Nature remains neutral with regard to jurisdictional claims in published maps and institutional affliations. 